\title{
LOS NUEVOS RETOS DE LAS ONGS ESPAÑOLAS PARA LA PREVENCIÓN DE LA CEGUERA
}

\section{THE NEW CHALLENGES OF THE SPANISH NGOS FOR THE PREVENTION OF BLINDNESS}

\author{
YANGÜELA-RODILLA $J^{1}$
}

Los días 26 y 27 de octubre de 2007, se celebró en Logroño el I Congreso Internacional para la Prevención de la Ceguera en Países en Desarrollo, organizado por nuestra ONG, Fundación Visión Mundi, como respuesta al creciente número de acciones promovidas en el exterior por oftalmólogos y ONGs españolas y también ante la aparición de patologías oculares a las que no estamos habituados, por el fenómeno de la inmigración. Nuestro objetivo era ser un punto de encuentro donde nos pudiéramos conocer, formarnos y tratar de aunar esfuerzos para mejorar la calidad de las acciones que realizamos en diferentes lugares del Mundo.

En el mundo hay más de 260 millones de personas afectadas por problemas severos de visión. De éstas, 37 millones están ciegas, más de 124 millones padecen baja visión por un problema médico y otros 100 millones más por defectos de refracción. Un 90 por ciento de las personas afectadas de ceguera vive en países en desarrollo, donde la posibilidad de quedarse ciego es entre 5 y 10 veces mayores que en los países industrializados. Estas cifras van en aumento: proyecciones de la OMS indican que la ceguera puede afectar a más de 75 millones de personas en el año 2020, como consecuencia del crecimiento demográfico y del envejecimiento de la población, a menos que se emprendan medidas urgentes y coordinadas.

La OMS considera que junto con las vacunaciones, la lucha contra la ceguera es la acción sanitaria más eficaz para luchar contra la pobreza. En muchos países pobres las personas ciegas son apartadas de la sociedad, «bocas sin manos», que dependen de un lazarillo para poder sobrevivir. Un niño que no ve bien no va a poder educarse adecuadamente y va a ver limitado todo su futuro. El $60 \%$ de los ciegos son mujeres. En muchas culturas, es la mujer la que se encarga de la educación de los niños, con lo que su falta de visión va a perpetuar la espiral del subdesarrollo en las siguientes generaciones.

Posiblemente ninguna otra especialidad médica tiene la posibilidad de hacer tanto por la gente necesitada como nosotros. Quizás por esto, somos cada vez mas los oftalmólogos que nos interesamos por la cooperación al desarrollo y que encontramos en ella un verdadero sentido a nuestro trabajo, en un momento en que la oftalmología está cada vez más mercantilizada.

Más de 120 oftalmólogos tuvimos la oportunidad de compartir unas horas en Logroño. Tras un sencillo acto inaugural a cargo de las Autoridades Regionales del Gobierno de la Rioja y del Profesor Murube del Castillo, en nombre de la SEO, asistimos a un curso de oftalmología tropical a cargo de la Dra. Patel, del Instituto de oftalmología Tropical de Londres, la Dra. Lewallen del Kilimanjaro Centre of Community Ophthalmology y el Dr. Aravind de India. Por la tarde la Dra. García Sandoval y los Dres. Abularach y Díaz del Hospital Hernández Vera de Bolivia, actualizaron nuestras técnicas en cirugía de tracoma, pterigium y cirugía de catarata mediante pequeña incisión manual, respectivamente.

Tras un emotivo homenaje al Dr. Ventakaswamy, fundador del Hospital Aravind de India, el sábado por la mañana tuvimos la oportunidad de escuchar y aprender de las experiencias exitosas de lucha contra la ceguera en algunos de los países más pobres del Mundo: en el sur de la India (Hospital Aravind), Tanzania (Kilimanjaro Eye Hospital), Paraguay, Bolivia.

\footnotetext{
1 Oftalmólogo. Fundación Hospital Alcorcón. Madrid. Presidente Fundación Visión Mundi.

E-mail: jyanguela@visionmundi.org
} 
Descubrimos que todos estos proyectos tienen en común muchas cosas: el apostar por la formación de personal local, el uso de técnicas de cirugía de catarata efectivas y de bajo coste (pequeña incisión manual tunelizada), el que no son gratuitos sino que los pacientes pagan acorde a su renta, la apuesta por la sostenibilidad, no sólo económica sino también en personal y recursos adquiridos localmente, planificación a largo plazo, el contar con una contraparte local de confianza...

Los expertos insistieron mucho en que la cooperación al desarrollo requiere formación específica para que ésta sea eficaz. No es lo mismo cooperación que caridad. Los programas de cirugía gratuita, donación de gafas ... son en la mayoría de los casos contraproducentes, ya que a su limitado impacto unen el que desincentivan la creación de proyectos sostenibles y educan a la gente en la cultura de la subvención, en vez de a luchar por sus propios medios para salir del subdesarrollo.

Para finalizar, realizamos un foro de ONGs españolas de lucha contra la ceguera, cuyas principales conclusiones serían:

- En la actualidad, entre 15-20 grupos diferentes de oftalmólogos españoles realizan algún tipo de cooperación, lo que da idea del enorme impulso que esta actividad va a tener en el futuro (en nuestra Web www.visionmundi.org podéis encontrar un directorio con las principales ONGs española).

- Debemos encontrar mecanismos para coordinarnos mejor y trabajar juntos. Al menos 4 ONGs trabajan en un país como Bolivia, con sólo 9 millones de habitantes, mientras una gran parte de Lati-
noamérica-Caribe, con casi 550 millones de habitantes, está desatendido.

- Nuestro impacto en la erradicación de la ceguera es muy limitado. Entre todos realizamos menos de 10.000 cirugías de catarata/año en todo el Mundo, cuando hacen falta de 4.000-5.000 cirugías /millón de habitante para disminuir la carga de ceguera por cataratas en un área concreta.

- Hay que apostar allí donde sea posible por el desarrollo sostenible: los países en desarrollo en los que está disminuyendo la ceguera, son aquéllos en los que se está apostando por capacitar personal local, en vez de acudir nosotros a realizar las cirugías. Debemos donde sea posible ir a formar, más que a operar.

- La cooperación al desarrollo en oftalmología va sin duda a tener una importancia cada vez mayor dentro de nuestra sociedad. De alguna manera somos embajadores de nuestra cultura y de nuestro país allí donde viajamos. Tenemos que encontrar mecanismos para que esta importante labor sea valorada y cuente con un respaldo decidido por parte de nuestras autoridades.

Desde nuestra Fundación Visión Mundi, intentaremos ayudar a que nuestras acciones tengan cada vez una mayor calidad y eficacia, haciendo bueno nuestro lema «Uniendo esfuerzos en la Lucha contra la ceguera». Por eso desde estas páginas os invito ya a todos, a acudir al II Congreso Internacional de Lucha Contra la Ceguera en Países en Desarro1lo, a celebrar en Logroño en el 2009, donde en un ambiente distendido, soñemos juntos en dejar un Mundo un poquito mejor a nuestros hijos. 